\title{
Improving the economic efficiency of vapor recovery units at hydrocarbon loading terminals
}

\author{
Vadim Fetisov ${ }^{1,}$, Amir H. Mohammadi ${ }^{2}$, Vladimir Pshenin ${ }^{1}$, Kirill Kupavykh ${ }^{1}$, and Dmitry Artyukh ${ }^{1}$ \\ ${ }^{1}$ Department of Petroleum Engineering, Saint Petersburg Mining University, 199106 Saint Petersburg, Russia \\ ${ }^{2}$ Discipline of Chemical Engineering, School of Engineering, University of KwaZulu-Natal, Howard College Campus, King George V \\ avenue, 4041 Durban, South Africa
}

Received: 29 November 2020 / Accepted: 12 April 2021

\begin{abstract}
The article discusses effective ways to reduce the cost of operating vapor recovery units and increase the financial result of their operation. The first method is based on regulation of the power-on time of the installation. The second method is based on using the potential energy of the fluid flow of the gravity section to supply the system equipment with energy. The potential savings on VRU maintenance will reduce the risks of payback of installations. The proposed methods will have a significant impact on society, as the possibility of a wider distribution of installations that protect the environment from emissions of volatile organic compounds into the atmosphere will become available.
\end{abstract}

\section{Introduction}

Oil transportation companies all over the world pay great attention to the problems of oil losses from evaporation when loading tankers. At the same time, instead of just caring about the environmental friendliness of existing oil terminals, there is an understanding of the economic benefits of careful treatment of resources (Ilinova et al., 2018). As part of the technological equipment of oil terminals, a common solution is Vapor Recovery Units (VRU) (Mulder, 2007). However, the introduction of such units in emerging economies is rare (Pashkevich and Petrova, 2019). This is due to the following reasons: significant cost, high (in some cases) energy intensity, long payback period, and minor legal restrictions (Litvinenko, 2020). This article aims to offer methods to reduce the operating costs of the operation of the VRU. It is expected that the methods will improve the economic efficiency of the VRU projects, which will affect the wide distribution of units in the future. The effect of the widespread implementation of the VRU will have a positive impact on the environment in the terminal area and improve the image of the companies (Lee et al., 2015).

The volumes of transshipment of oil and petroleum products through marine terminals, according to the reports of the Russian company "Transneft", have an upward trend (Fig. 1). However, at the same time, the volume of losses of liquid cargo transported is also increasing (Energy Institute, 2008). VOCs are known to be released

\footnotetext{
* Corresponding author: fetisov.vadym@gmail.com
}

into the atmosphere when loading a tanker are organic compounds of anthropogenic origin that can react with nitrogen oxides in sunlight and form ground level ozone. Groundlevel ozone is highly toxic to humans and is a strong environmental pollutant (Romasheva et al., 2018). For these reasons, Annex VI to MARPOL 73/78 entered into force in 2005, which limits the release of pollutants from ships. For example, rule 15 requires that tankers and terminals have a vapor collection system. For this reason, there is a sufficient amount of work on VRU.

Analyzing the work related to the protection of the environment from VOCs at terminals, we note that there is a concept of considering this topic from the point of view of increasing technological efficiency and monitoring the work of the VRU (Gruber, 2019; Helmig et al., 2014; Karbasian et al., 2017; Klimont et al., 2000; Korshak et al. 2019; Krummenauer et al., 2018; Liang et al., 2018; Pannucharoenwong et al., 2018; Rudd and Hill, 2001; Seo et al., 2000; Shibuya, 2014; Shipley, 2011). Nevertheless, even with the development of such measures, the prevalence of VRU at terminals in many emerging economies remains low (Tcvetkov et al., 2020).

VRU has a very high capital cost. In addition to capital costs, operating costs are also allocated, which include: the cost of electricity consumed, maintenance and repair costs, as well as planned replacement of adsorbent or liquid nitrogen (depending on the technology used) (Chahartaghi and Sheykhi, 2019). In this case, it is quite risky to invest monetary assets in VRU implementation projects, as they can take a long time to pay off (more than 5 years). 


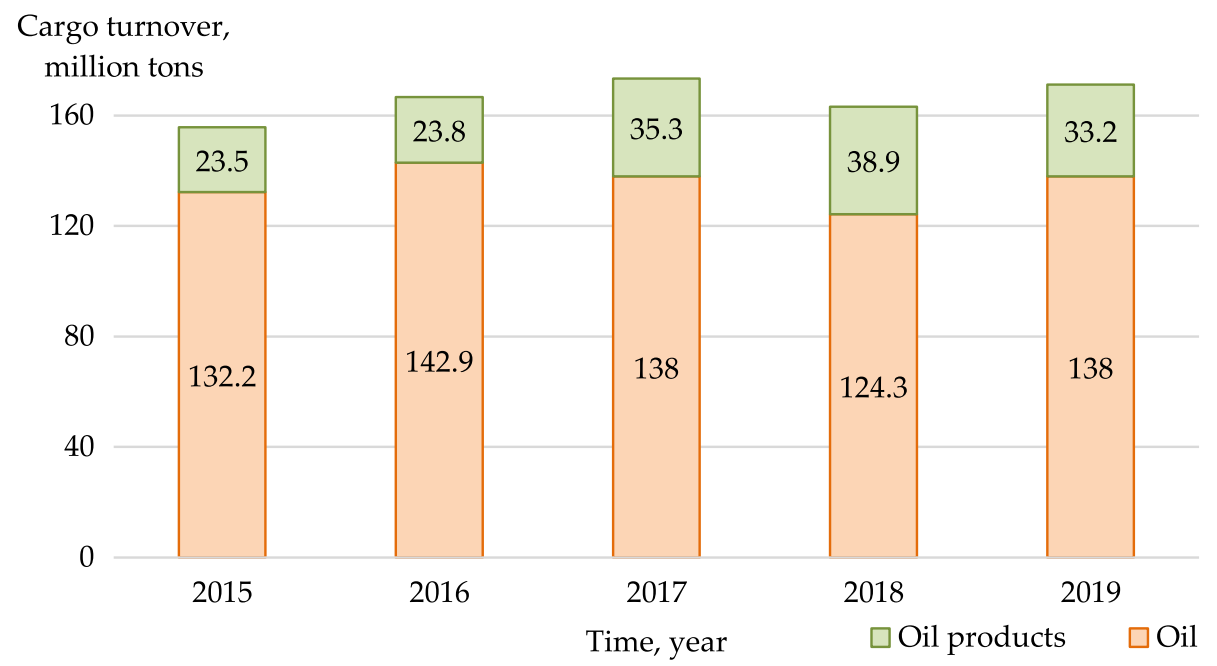

Fig. 1. Dynamics of cargo turnover of oil and oil products at marine terminals.

The low prevalence of installations is associated with the high energy intensity of VRU that reduces their widespread use in many developing economies included in the MSCI index (Litvinenko, 2020). The question of creating methods to improve the economic efficiency of projects for the implementation of URP becomes obvious.

Two approaches are proposed to address the lack of methods for reducing operating costs. The first approach is based on resource saving due to the use of the potential energy of the liquid flow in the case of a gravity section. The second approach is based on the inclusion in the work of the VRU later than the start of loading of the tanker for the specified time. In the second case, there is a deliberate loss of VOCs at the beginning of loading, which is justified in the course of the study.

This article is organized as follows: Section 2 describes the proposed methods for improving the economic efficiency of VRUs projects; Section 3 presents research with relevant calculations and graphs; Section 4 gives the results of research and Section 5 introduces the conclusions of this article.

\section{Materials and methods}

\subsection{Method of reducing electricity consumption}

Vapor Recovery Units (VRUs) are characterized by high operating costs due to significant energy consumption (Ahn et al., 2019). This fact creates the challenge of developing methods to reduce the consumption of VRUs electrical energy.

It is proposed to reduce the energy consumption of units by determining the rational time of switching on the VRU during the loading operation of the tanker to improve the economic performance of the VRU.

Starting a VRU means turning on the gas blower equipment that transports VOCs to the VRU. That is, after the start of loading the tanker, but before the start of switching on the gas blower, there will be a deliberate loss of VOCs until the time of rational capture of VOCs. The proposed method is universal for any conditions where the VOC emission tax is not large.

In addition, the definition of rational time should be defined for each specific loading of the tanker, while the parameters from case to case can be quite different, then the calculation of rational time will be shown in a specific example. The definition of rational-time gas blowers will depend on such parameters as: efficiency of VRU, volume flow loading of hydrocarbons, the volume of the tanker, the resistance of the transport system of vapor on the VRU, the cost of the captured VOCs and taxes for emissions of VOCs into the atmosphere.

The cost-effectiveness of the method is estimated based on some actual data obtained from the VRU adsorption technology (Tab. 1) operating at the oil loading terminal in Russia (the VOCs emission tax is taken into account at the rate existing in Russia). The Aframax tanker is used as an example. This type of vessel is chosen because of its universal capacity and deadweight, which allows this vessel to access most ports around the world. The technical specifications are given in Table 2.

\subsection{Resource saving method of the VRU system}

Improving the economic efficiency of VRUs projects is also achieved by resource saving in the VRU system (Liu et al., 2015; U.S. EPA, 2006). The paper suggests the idea of reducing the power consumption of the VRU system at the terminal when loading hydrocarbons into a tanker by using the potential energy of the fluid flow of the gravity section. The proposed method is not universal, since the gravity section is not found at all terminals. This method is applicable to terminals located on a significant elevation of the reservoir Park in relation to the coastline and the presence of a gravity section. It is proposed to install a bypass line with the introduction of a centrifugal unit that communicates with the VRU gas blower via a shaft and a multiplier. 
Table 1. Actual VRU data of the adsorption technology when loading the Aframax tanker.

\begin{tabular}{lcc}
\hline $\begin{array}{l}\text { The volumetric flow } \\
\text { rate gas mixture, } \mathrm{m}^{3} / \mathrm{h}\end{array}$ & $\begin{array}{c}\text { Degree of } \\
\text { purification, } \%\end{array}$ & $\begin{array}{c}\text { Power, } \\
\mathrm{kW}\end{array}$ \\
\hline 10000 & 97 & 550 \\
10500 & 93 & 670 \\
11000 & 91 & 700 \\
11500 & 89 & 720 \\
12000 & 86 & 750 \\
12500 & 84 & 820 \\
13000 & 84 & 860 \\
13500 & 82 & 890 \\
\hline
\end{tabular}

Table 2. Technical characteristics of the Aframax type tanker.

\begin{tabular}{lcc}
\hline Parameter & Unit & Value \\
\hline Total volume & $\mathrm{m}^{3}$ & 131617 \\
Dimensions & $\mathrm{m}$ & $241 \times 44$ \\
Method for inerting the gas space & - & Exhaust gases \\
\hline
\end{tabular}

Table 3. Data for the economic evaluation of the method.

\begin{tabular}{lcc}
\hline Parameter & Value & Unit \\
\hline Length of the pipeline route & 1500 & $\mathrm{~m}$ \\
Pipeline diameter & 720 & $\mathrm{~mm}$ \\
Loading volume flow rate & 1000 & $\mathrm{~m}^{3} / \mathrm{h}$ \\
Geodetic height & 210 & $\mathrm{~m}$ \\
Grade of oil & ESPO & - \\
Oil density at $20{ }^{\circ} \mathrm{C}$ & 852 & $\mathrm{~kg} / \mathrm{m}^{3}$ \\
Kinematic viscosity at $20{ }^{\circ} \mathrm{C}$ & 6.95 & $\mathrm{~m}^{2} / \mathrm{s}$ \\
Cost of $1 \mathrm{kWh}$ of electricity & 0.08 & U.S. dollars $(\$)$ \\
\hline
\end{tabular}

The economic efficiency of the proposed method is estimated in the operating conditions of the VRU at the ESPO oil loading terminal in Russia. The data used in calculating the effectiveness of the method are shown in Table 3.

\section{Case study}

\subsection{Determination of the optimal activation time of the vapor recovery unit during loading}

The aim of the method is to reduce the operating costs of Vapor Recovery Units (VRUs). To achieve the stated goal, it is necessary to analyze the available reserves for energy saving when operating VRUs at oil loading terminals. Therefore, it is necessary to highlight the features of crude oil and oil product vapor emissions from the cargo tank and refer to Figure 2.

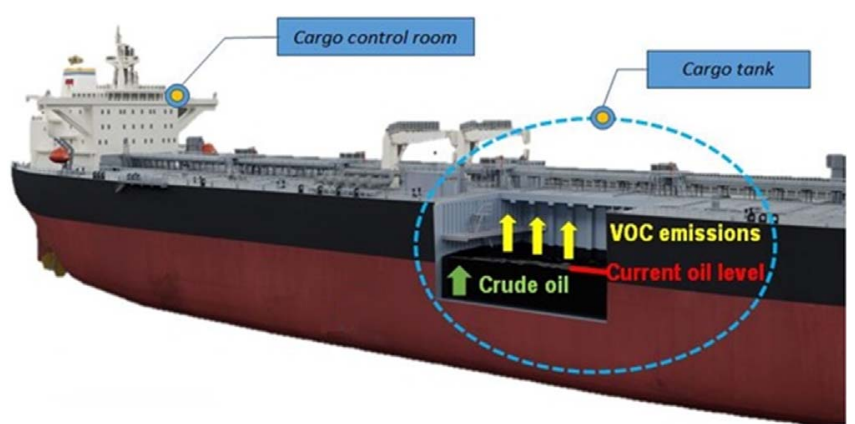

Fig. 2. Tanker loading.

At the initial stage of displacement of the gas mixture from the cargo tanks, the lean mixture is released according to the VOC content. This fact is confirmed by the analysis of the actual data when loading the tanker. Figure 3 shows the dependence of the mass content of hydrocarbons in the displaced gas mixture on the relative loading time for an Aframax tanker. Relative loading time:

$$
\tau=\frac{t}{t_{\text {tot }}}
$$

$t_{\text {tot }}$ - total loading time, s; $t$ - the current time in loading, s.

The graph shown in Figure 3 confirms that at the initial stage of loading, gas mixture containing a small amount of VOCs is displaced. At the same time, in world practice, at terminals with VRUs, installations are switched on either before the tanker starts loading (up to half an hour), or during the start of loading (Balakheli et al., 2020). At the same time, enterprises incur high operating costs due to the high energy consumption of equipment included in the VRU system. Therefore, in adsorption technologies a large share of electricity consumption accounted for vacuum pumps, in absorption to the pumps the absorbent, at cryogenic pumps, coolant feed and some other equipment that consume electricity (Shibuya, 2014).

The idea of the method is to turn on the installation later for some rational time after the start of loading, since at the beginning of loading the mass consumption of hydrocarbons is insignificant.

To assess the economic effect of this method, a methodology is proposed. The financial result of the VRUs operation when the installation is turned on after the start of loading by a certain value:

$$
F_{\text {result }}=I-E_{\text {power }}-D ;
$$

$I$ - income from the recovered oil, U.S. dollars $(\$) ; E_{\text {power }}-$ the cost of electric power consumed by the VRU, U.S. dollars $(\$) ; D$ - cost expression of damage from emissions of $\mathrm{C}_{1}-\mathrm{C}_{10}$ hydrocarbons into the atmosphere, supplemented by lost profits from irretrievably lost oil, U.S. dollars (\$). Income from the recovered oil:

$$
I=\sigma_{\text {oil }} \cdot \int_{\tau_{\text {start }}}^{\tau_{\text {end }}} Q \cdot m_{y} \cdot \frac{S}{100} \mathrm{~d} t
$$




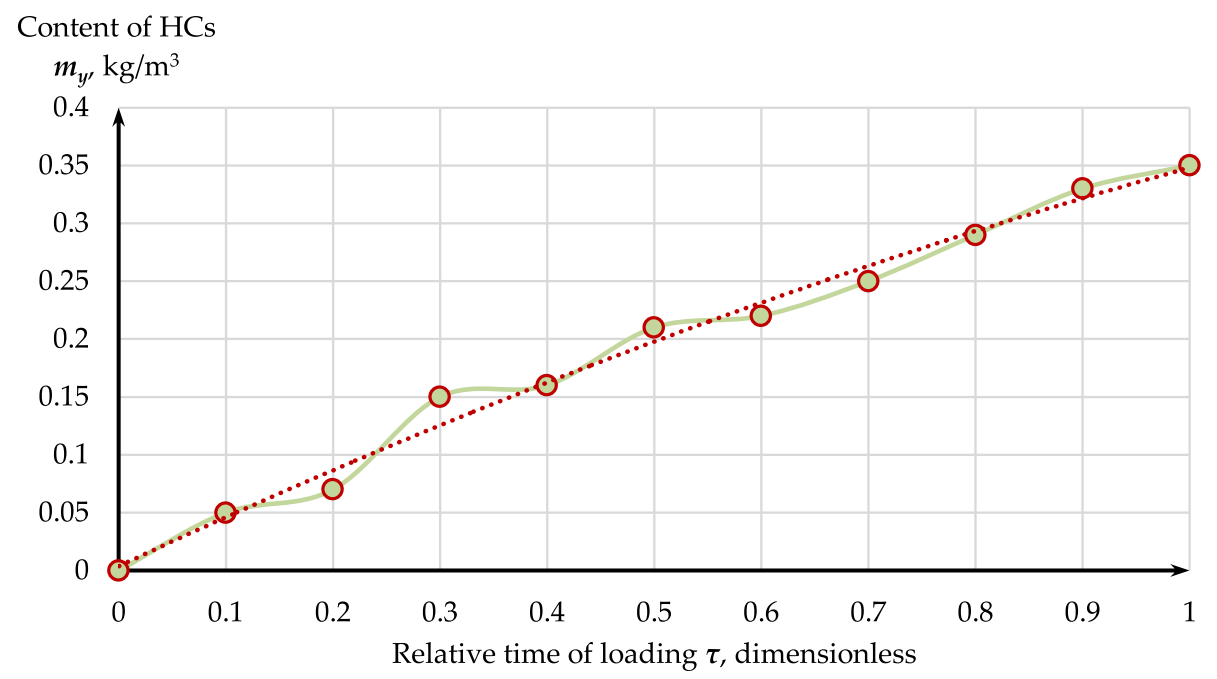

Fig. 3. Graph of the dependence of the VOC content in gas mixture on the loading time of the tanker.

$\sigma_{\text {oil }}$ - cost of recovered oil, U.S. dollars $(\$) ; \tau_{\text {start }}-$ start time of recovery process, $\mathrm{s} ; \tau_{\text {end }}$ - time of the ending of the recovery process, s; $Q$ - vapors flow rate, $\mathrm{m}^{3} / \mathrm{h}$; $m_{y}$ - the weight content of hydrocarbons in gas mixture, $\mathrm{g} / \mathrm{m}^{3} ; S$ - recovery rate, dimensionless; $t$ - time, s.

The cost of electric power consumed by the vapor recovery unit:

$$
E_{\text {power }}=\sigma_{\text {power }} \cdot \int_{\tau_{\text {start }}}^{\tau_{\text {end }}} N \mathrm{~d} t \text {; }
$$

$\sigma_{\text {power }}-$ cost of 1 kilowatt-hour, U.S. dollars $(\$) ; N-$ power of vapor recovery unit as function of time, $\mathrm{kW}$.

This method implies the loss of a certain amount of gas mixture containing VOC, which is a missed opportunity. In addition, there are tax charges for non-captured hydrocarbons. Monetary damage from hydrocarbon emissions into the atmosphere and lost profits from irretrievably lost oil:

$$
\begin{aligned}
D= & \left(\sigma+\sigma_{\text {oil }}\right) \cdot \int_{\tau_{\text {start }}}^{\tau_{\text {end }}} Q \cdot m_{y} \cdot\left(1-\frac{S}{100}\right) \mathrm{d} t \\
& +\left(\sigma_{\text {power }}+\sigma_{\text {oil }}\right) \cdot \int_{0}^{\tau_{\text {start }}} Q \cdot m_{y} \mathrm{~d} t ;
\end{aligned}
$$

$\sigma$ - fees $\mathrm{C}_{1}-\mathrm{C}_{10}$ hydrocarbons in $1 \mathrm{~m}^{3}$ of emissions, U.S. dollars $(\$)$.

Income from the recovered oil determined by Formula (3) depends on the values of the vapor flow rate over time. The vapors flow rate depends on the flow rate of oil loading and the excess flow ratio. The key process that determines the volume flow rate of the displaced gas mixture is the pressure in the gas space. When loading, the pressure inside the tanker's cargo tank increases not only due to the reduction of the gas space, but also due to the intensive evaporation of hydrocarbons. It is proved that during loading, the volume flow rate of the displaced gas mixture often exceeds the volume flow rate of loading liquid hydrocarbons (Dmitriev et al., 2019). This ratio is also called relative flow, which is determined by the Formula (6):

$$
k_{i}=\frac{Q}{Q_{\text {loading }}} ;
$$

$Q_{\text {loading }}$ - volume flow rate of loading of hydrocarbons, $\mathrm{m}^{3} / \mathrm{h}$.

Figure 4 shows graph of the relative gas mixture flow rate versus the relative time. The graph shown in the figure is based on data obtained when loading an Afromax tanker at a terminal in Russia.

Income from the recovered oil, determined by Formula (3), also depends on the capacity of the installation and the degree of steam purification, which in turn depend on the consumption of hot water. Table 2 shows the actual dependencies necessary for further calculations, which are shown in the combined graph 5 . Figure 5 shows that the higher the consumption, the worse efficiency of gas cleaning at the vapor recovery unit, and the higher the energy costs.

The next step is to apply the tanker's input data, the VRU data at the terminal from Figures 3-5, the tax rate for hydrocarbon emissions for Russia, the cost of electricity in Russia, and the cost of oil on the stock market. Equation (2) is solved analytically or using software packages. The result of this example is shown in Figure 6.

The optimal time for switching on the VRU is determined according to the graph in Figure 6 in the extremum of the function, and the benefit of the applied method for one loading of a particular tanker is estimated.

Figure 7 shows a graph of the power consumption versus the absolute loading time in order to estimate the power savings when the unit is switched on after the optimal time.

Determining the area of the shaded shape under the line of the function graph, bounded by the corresponding time value, will determine the energy saved.

Keep in mind that this method also includes capital investments. The investment consists in reconfiguring the VRU programme logic controller and configuring the operator's automated workplace. The cost will be approximately 10000 dollars. Therefore, an assessment of the economic effect of implementing the method is necessary 


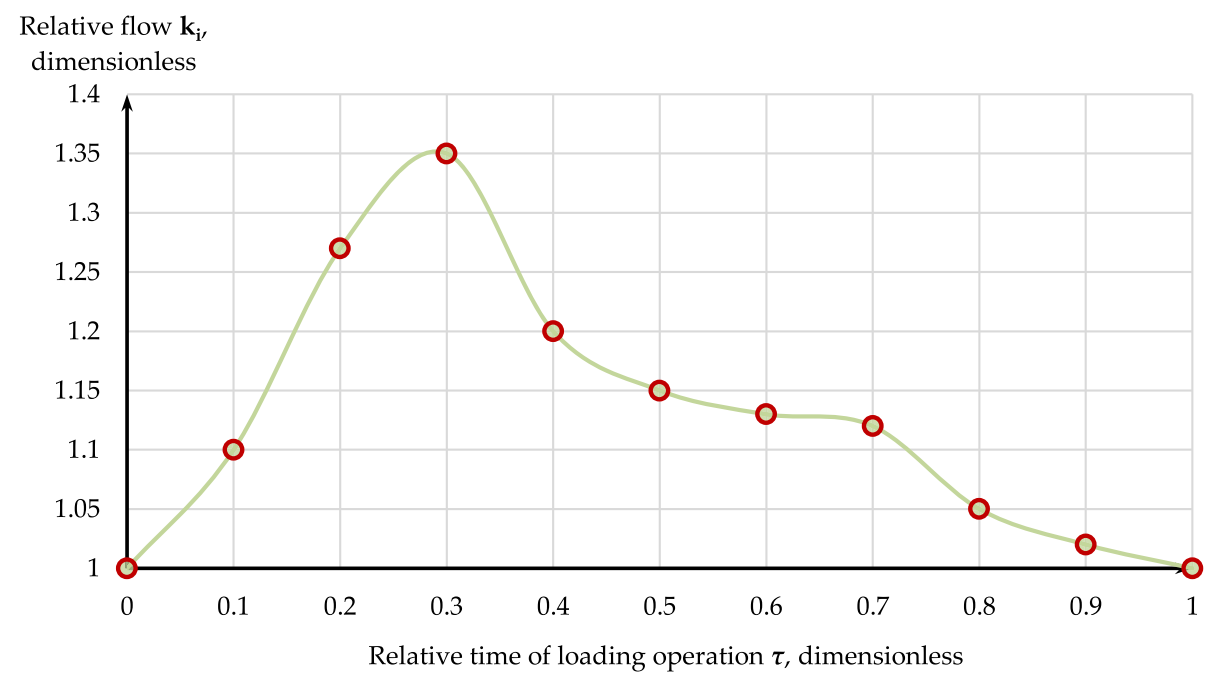

Fig. 4. The change in the volume flow rate of gas mixture during the loading operation.

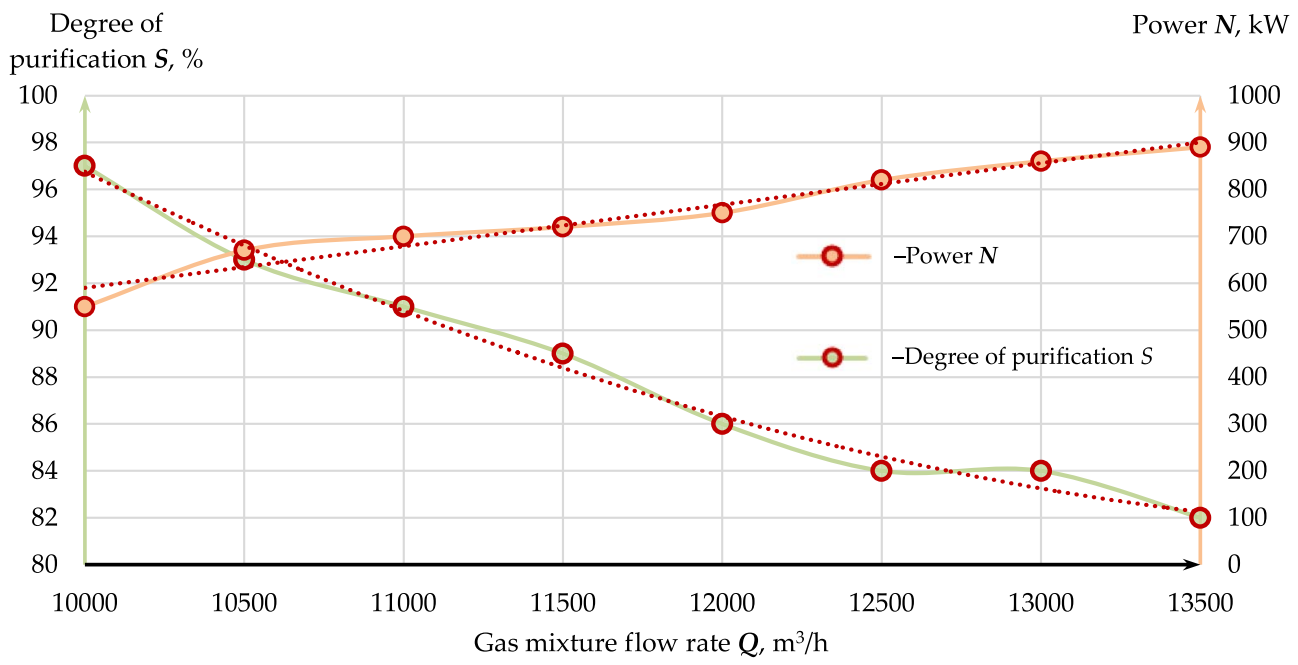

Fig. 5. Dependence of the parameters of the VRU operation on the flow rate of the gas mixture.

(Tcvetkov et al., 2020), P.Assessment of the economic effect of the proposed measure can be estimated by determining the payback period of cash and accumulated Net Present Value (NPV) for 5 years.

NPV is based on Formula (7), where one-time cash outflows were $\$ 10000$, annual inflows were $\$ 2100$, and the discount rate was $12 \%$. The result is shown in the Figure 8:

$$
\mathrm{NPV}=\sum_{t=1}^{n} \frac{\mathrm{CF}_{t}}{(1+R)^{t}}-\mathrm{IC}
$$

\subsection{Concept of a device for reducing the need for electricity vapor recovery unit}

Significant operating costs when using a VRU are associated with the use of equipment that provides gas mixture transport to the VRU. A resource-saving method for ensuring the operation of the gas blower without using electric energy is proposed. Since the gas blower is part of the system of each vapor recovery technology, the proposed method is universal for any VRU technology, but can only be used for loading liquid hydrocarbons by gravity from a certain height above sea level.

There are cases when, due to the mountainous landscape, hydrocarbons enter the oil terminal from a significant height relative to the coastline. With this loading option, a slope of the liquid flow occurs, which provides the necessary flow rate and pressure of the pumped liquid and, as a result, a gravity section is formed. Loading tankers by gravity is not rarely used in practice (Tuttle and Young, 2011). For example, in Russia, oil and oil products at the Sheskharis and Kozmino terminals are delivered by gravity from the heights of 300 and $210 \mathrm{~m}$, respectively. Images of terminals are shown in Figure 9. These elevation levels create even 


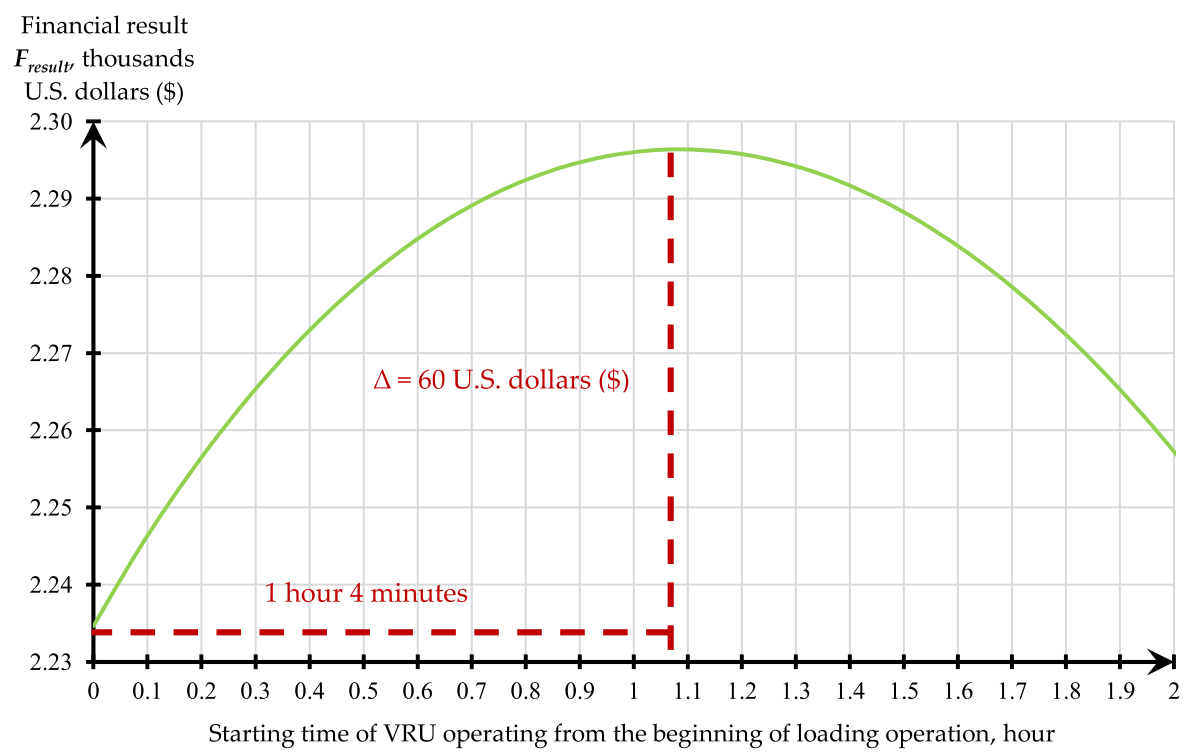

Fig. 6. Dependence of the financial result on the loading start time.



Fig. 7. Graph of VRU power consumption during loading.

higher pressure values than are necessary for loading the tanker, which are reduced by pressure regulators (Quoilin et al., 2011). For this reason, there is a loss of potential flow energy, which is proposed to be used in this work (Cui et al., 2017).

In this method, it is proposed to create a device that will convert the energy of the liquid flow that is not used at the terminals into the necessary energy of rotation of the impeller of the gas blower included in the VRU system.

The idea of the method is to connect the bypass line with rigidly installed centrifugal units to the oil loading pipeline. A shaft is installed inside the centrifugal unit, which is mechanically fixed through a multiplier to the shaft of the centrifugal gas blower installed on the vapor removal gas pipeline.

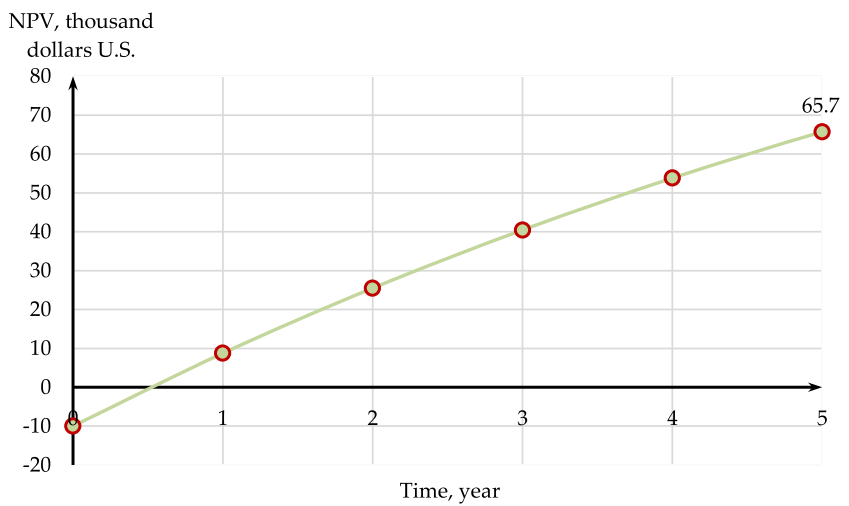

Fig. 8. Graph of accumulated net present value for optimal VRU turn-on time. 


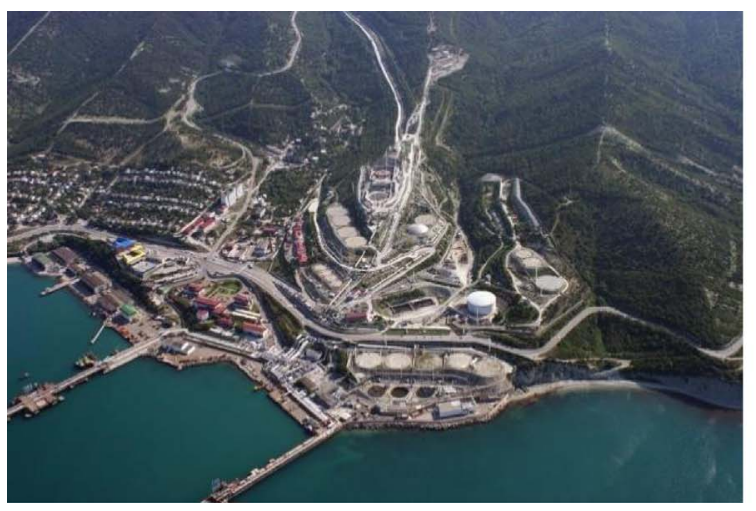

a)

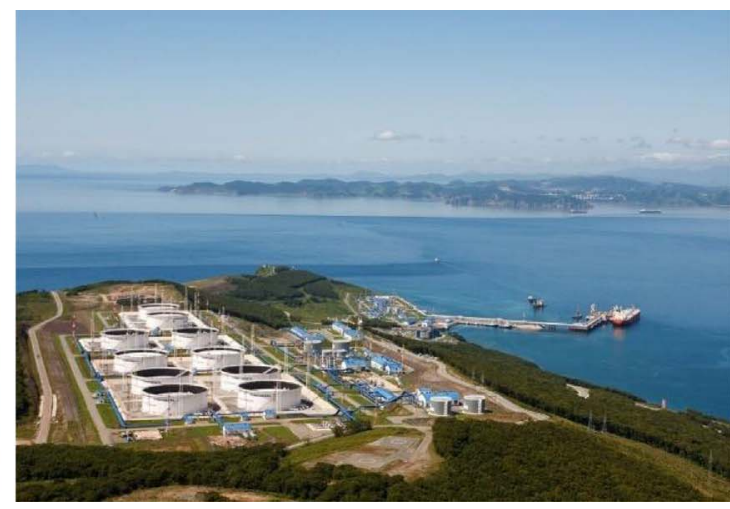

b)

Fig. 9. Images of marine terminals: (a) Sheskharis in the Krasnodar territory and (b) Kozmino in the Primorsky territory.

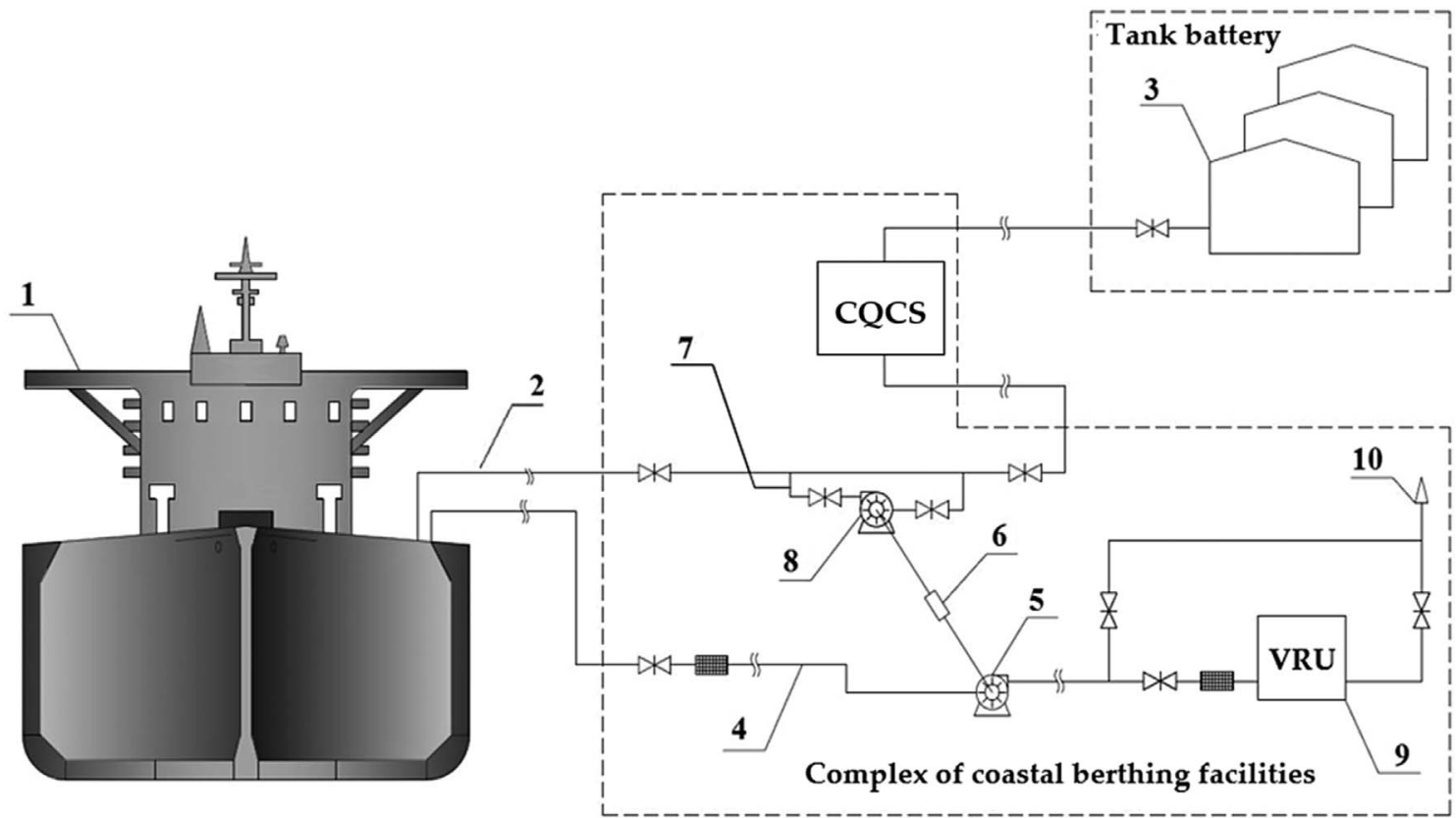

Fig. 10. General view of the device for capturing oil and petroleum products vapors at terminals. 1 - tanker; 2 - oil filling pipeline; 3 - reservoirs; 4 - the piping of the gas phase; 5 - gas blower; 6 - multiplier; 7 - bypass filling line; 8 - a centrifugal unit; 9 - vapor recovery unit; 10 - gas supply pipeline for purging.

Below is a description of the technological scheme of vapor removal with the proposed device in Figure 10. During the loading operation of the tanker 1, oil or petroleum products are delivered via the oil filling pipeline 2 after passing the Crude Quality Control System (CQCS) from the tank farm 3 by gravity. Oil or oil products vapors from the tanker are diverted through the gas phase pipeline 4 to the gas blower 5 . The gas blower 5 is connected via a multiplier 6 through a bypass line 7 to a centrifugal unit 8 . The gas blower 5 provides transportation of gas mixture to the VRU 9 and then to the gas vent stack 10 through the gas phase pipeline 4 .
The potential energy of the oil being poured, which was previously irretrievably lost, is converted into the kinetic energy of rotation of the gas blower shaft, which saves electrical energy for vapor removal.

The economic benefit of this method over the one loading:

$$
F_{\text {result }}=\mathrm{PS} \cdot \sigma_{\text {power }}
$$

PS - amount of power saving, U.S. dollars (\$).

Amount of power saving:

$$
\mathrm{PS}=\rho \cdot g \cdot\left(\Delta z-h_{\mathrm{loss}}\right) \cdot \eta ;
$$




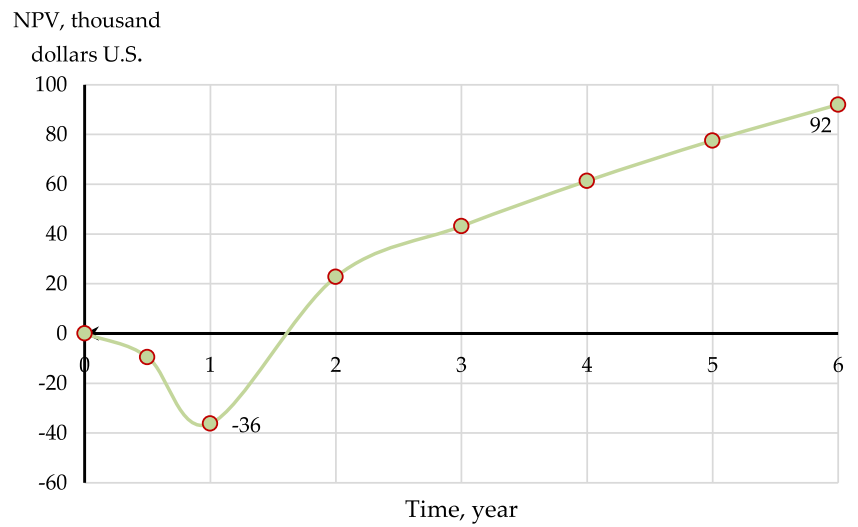

Fig. 11. Graph of accumulated discounted revenue for a gravity section liquid energy conversion device.

$\rho$ - density of oil or petroleum product, $\mathrm{kg} / \mathrm{m}^{3} ; g-$ acceleration of gravity, $\mathrm{m} / \mathrm{s}^{2} ; \Delta z$ - geodetic height, $\mathrm{m} ; h_{\text {loss }}$ - hydraulic losses in the loading pipeline, $\mathrm{m} ; \eta$ - efficiency of the centrifugal unit, dimensionless.

Head loss:

$$
h_{\mathrm{loss}}=\lambda \cdot \frac{L}{D} \cdot \frac{v^{2}}{2 \cdot g}+\xi \cdot \frac{v^{2}}{2 \cdot g}
$$

$\lambda$-coefficient of hydraulic resistance, dimensionless; $\xi-$ coefficient of local resistances, dimensionless; $L$ - length of the pipeline route, $\mathrm{m} ; D$ - pipeline diameter, $\mathrm{m} ; v-$ the fluid velocity, $\mathrm{m} / \mathrm{s}$.

It is proposed to evaluate the implementation of the proposed device based on the data set out in the Table 3.

Assuming the fluid flow mode is turbulent in the area of hydraulically smooth pipes, the pressure loss according to Formula (10) will be approximately $55 \mathrm{~m}$. The efficiency is taken as the average for centrifugal units of $70 \%$. Then for one loading, about $911 \mathrm{kWh}$ is saved, or a saving of $\$ 73$. With an average number of shipments per year equal to 350 , the benefit is approximately $\$ 2500$.

Capital expenditures are required to implement the proposed installation. The capital cost of installing the bypass line, the centrifugal unit, and the multiplier is estimated at approximately $\$ 40000$. The costs are significant, so the economic effect of implementing the device was estimated using the Formula (7) at a discount rate of $12 \%$. The result is shown on the graph in Figure 11.

\section{Results}

1. The maximum financial result from the operation of the VRU has achieved not when it is turned on simultaneously with the start of the loading operation, but after $1 \mathrm{~h}$ and $4 \mathrm{~min}$.

2. The proposed solution for managing the turn-on time of the vapor recovery unit reduces energy consumption per loading operation by approximately $6 \%$.
3. There has been a positive economic effect on the considered example of using the optimal VRU turn-on time. The net present value accumulated over 5 years was $657000 \$$, during the first year the project has paid off.

4. Using the potential energy of the fluid flow of the gravity section will be cost-effective only if the value of the height of the geodetic mark is greater than the values of hydraulic losses during loading of hydrocarbons.

5. The positive economic effect has occurred on the example of implementing a resource-saving device with a multiplier in the VRU system. The net present value accumulated over 5 years was $92000 \$$, during the first year of operation of the device the project has paid off.

\section{Conclusion}

The article has discussed methods for improving the economic efficiency of projects for Vapor Recovery Units (VRUs) at oil and petroleum products loading terminals.

One of the methods considered in this paper is to reduce the cost of operating a VRU, based on regulating the operation depending on the defining parameters. The advantage of this method is its versatility for any VRU technology. Based on the study, it is concluded that switching on the VRU later than the start of loading can have a significant economic effect by reducing energy consumption. The disadvantage of this method is that when it is used, a certain amount of hydrocarbon vapors is lost, which are harmful to the environment. Therefore, this method is not relevant in countries with developed economies, for example, in European countries, where the rates of tax for VOC emissions are hundreds of times higher than in many emerging market economies. On the one hand, the proposed measure has a negative impact on the environment, on the other hand, the method reduces the risks of project payback, and in developing countries this could serve as an incentive for rapid implementation of VRU in terminals, which would have an absolutely positive impact on the environment.

The second method is proposed to convert the potential energy of the loading oil into the kinetic energy of rotation of the gas blower shaft. Note that this device does not necessarily fully provide the gas blower with the necessary energy, in this case, the electric motor of the gas blower will make up for the missing energy. At the same time, the device will significantly reduce the power consumption of the gas blower, and therefore the entire VRU system. The advantage of this method is that it is universal for any VRU technology, does not depend on the degree of VOCs emission control. The disadvantage is the limited scope of this method, since its implementation requires a gravity section and a height difference exceeding the hydraulic losses of hydrocarbon loading pipelines.

In the future, the results of this work can be used to improve the efficiency of existing VRUs at terminals, as well as to create a highly efficient VRU. 


\section{Competing interests}

The authors declare that they have no competing interests.

\section{References}

Ahn H., Freihaut J.D., Rim D. (2019) Economic feasibility of combined cooling, heating, and power (CCHP) systems considering electricity standby tariffs, Energy 169, 420-432. https://doi.org/10.1016/j.energy.2018.11.126.

Balakheli M.M., Chahartaghi M., Sheykhi M., Hashemian S.M., Rafiee N. (2020) Analysis of different arrangements of combined cooling, heating and power systems with internal combustion engine from energy, economic and environmental viewpoints, Energy Convers. Manage. 203, 112253. https://doi.org/10.1016/j.enconman.2019.112253.

Chahartaghi M., Sheykhi M. (2019) Energy, environmental and economic evaluations of a CCHP system driven by Stirling engine with helium and hydrogen as working gases, Energy 174, 1251-1266. https://doi.org/10.1016/j.energy.2019.03.012.

Cui Y., Geng Z., Zhu Q., Han Y. (2017) Review: Multi-objective optimization methods and application in energy saving, Energy, Elsevier 125(C), 681-704. https://doi.org/10.1016/ j.energy.2017.02.174.

Dmitriev M.E., Sadreeva K.K., Pshenin V.V., Gaysin M.T. (2019) Dermination of the VOC vapor relative flow rate during tanker loading operations, Transp. Storage Oil Prod. Hydrocarb. 1, 10-13. https://doi.org/10.24411/0131-4270-2019-10102.

Energy Institute (2008) Vapor recovery units-guidance on preventing and controlling temperature excursions in carbon beds, 2nd edn., Energy Institute, London.

Gruber H. (2019) Proposals for a digital industrial policy for Europe, Telecommun. Policy, Elsevier 43, 2, 116-127. https://doi.org/10.1016/j.telpol.2018.06.003.

Helmig D., Thompson C.R., Evans J., Boylan P., Hueber J., Park J.H. (2014) Highly elevated atmospheric levels of volatile organic compounds in the Uintah Basin, Utah, Environ. Sci. Technol. 48, 4707-4715. https://doi.org/10.1021/es405046r.

Ilinova A., Cherepovitsyn A., Evseeva O. (2018) Stakeholder management: An approach in CCS projects, Resources 7, 83. https://doi.org/10.3390/resources7040083rces.

Karbasian H.R., Kim D.Y., Yoon S.Y., Ahn J.H., Kim K.C. (2017) A new method for reducing VOCs formation during crude oil loading process, J. Mech. Sci. Technol. 31, 17011710. https://doi.org/10.1007/s12206-017-0318-7.

Klimont Z., Amann M., Cofala J. (2000) Estimating costs for controlling emissions of Volatile Organic Compounds (VOC) from stationary sources in Europe. IIASA Interim Report IR00-051. https://www.jstor.org/stable/resrep15727.

Korshak A.A., Gaisin M.T., Pshenin V.V. (2019) Method of structural minimization of the average risk for identification of mass transfer of evaporating oil at tanker loading. Neftyanoe Khozyaystvo - Oil Industry 2019, 10, 108-111. https://doi. org/10.24887/0028-2448-2019-10-108-111.

Krummenauer E.J., Rossini E.G., de Souza J., Beluco A. (2018) Estimation of emissions of volatile organic vapors from parameters measured in a fuel loading terminal, Int. Energy Environ. Found. 9, 2, 137-144. http://hdl.handle.net/10183/183245.

Lee K., Boufadel M., Chen B., Foght J., Hodson P., Swanson S., Venosa A. (2015) Expert panel report on the behaviour and ecological impacts of crude oil released into aqueous environments, Royal Society of Canada, Ottawa, ON. ISBN 978-1-928140-02-3.

Liang J., Sun L., Li T. (2018) A novel defrosting method in gasoline vapor recovery application, Energy 163, 751-765. https://doi.org/10.1016/j.energy.2018.08.172.

Litvinenko V. (2020) Digital economy as a factor in the technological development of the mineral sector, Nat. Resour. Res. 29, 3, 1521-1541. https://doi.org/10.1007/s11053-01909568-4.

Liu X., Zhu J., Zhang S., Hao J., Liu G. (2015) Integrating LINMAP and TOPSIS methods for hesitant fuzzy multiple attribute decision making, J. Intell. Fuzzy Syst. 28, 1, 257269. https://doi.org/10.3233/IFS-141296.

Mulder T. (2007) VOC recovery systems, Hydrocarb. Eng. 12, 6, 37-40.

Pannucharoenwong N., Chabuanoi T., Benjapiyaporn C., Echaroj S. (2018) The optimal design of prototype to replace the Vapor Recovery Unit (VRU) using computational fluid dynamic analysis, Int. J. Appl. Eng. Res. 13, 3, 1623-1627. https://ripublication.com/ijaer18/ijaerv13n3_12.pdf.

Pashkevich M.A., Petrova T.A. (2019) Recyclability of ore beneficiation wastes at the Lomonosov deposit, J. Ecol. Eng. 20, 27-33. https://doi.org/10.12911/22998993/94919.

Quoilin S., Declaye S., Tchanche B.F., Lemort V. (2011) Thermo-economic optimization of waste heat recovery organic Rankine cycles, Appl. Therm. Eng. 31, 14-15, 28852893. https://doi.org/10.1016/j.applthermaleng.2011.05.014.

Romasheva N.V., Kruk M.N., Cherepovitsyn A.E. (2018) Propagation perspectives of $\mathrm{CO}_{2}$ sequestration in the world, Int. J. Mech. Eng. Technol. 9, 1877-1885.

Rudd H.J., Hill N.A. (2001) Measures to reduce emissions of VOCs during loading and unloading of ships in the EU. Report no. AEAT/ENV/R/0469 Issue 2. Produced for the European Commission DG Environment. https://ec.europa. eu/environment/air/pdf/vocloading.pdf.

Seo J.W., Oh M., Lee T.H. (2000) Design optimization of a crude oil distillation process, Chem. Eng. Technol. 23, 157-164. https://doi.org/10.1002/(SICI)1521-4125(200002)23:2<157:: AID-CEAT157>3.0.CO;2-C.

Shibuya Y. (2014) Vapor recovery technique for crude oil ship loading - spray absorption, JFE Technical Report, No. 19, pp. 158-166. https://www.jfe-steel.co.jp/en/research/report/019/ pdf/019-29.pdf.

Shipley S. (2011) Developing an effective crude oil vapor recovery system, in: Port Technology International, Edition 49, Simon Shipley, Aker Cool Sorption (Aker Solutions), Glostrup, Denmark, pp. 80-82. https://www.porttechnology. org/wp-content/uploads/2019/05/80-82.pdf.

Tcvetkov P., Cherepovitsyn A., Makhovikov A. (2020) Economic assessment of heat and power generation from small-scale liquefied natural gas in Russia, Energy Rep. 6, 391-402. https://doi.org/10.1016/j.egyr.2019.11.093.

Tuttle W.N., Young J.W. (2011) An overview of marine vapour control system safety requirements, in: Port Technology International, Edition 34, pp. 156-159.

U.S. EPA (2006) Installing Vapor Recovery Units on Storage Tanks, Lessons Learned from Natural Gas Star Partners. United States Environmental Protection Agency Air and Radiation, Environmental Topics. https://www.epa.gov/ sites/production/files/2016-06/documents/ll_final_vap.pdf. 